\title{
Microbiological Investigation of Water Sources as Cause of Acute Watery Diarrhoea Outbreak in District of Mathura, India
}

\author{
Astha $^{1}$, Ankur Goyal $^{2}$, Sapna Gupta ${ }^{3}$, Sunil Kaushal ${ }^{4}$ \\ 1,2, (Department of Microbiology, S.N. Medical College, Agra, India) \\ ${ }^{3}$ PhD research scholar, Department of Microbiology, National Institute of Medical Sciences \& Research, \\ Jaipur, Rajasthan. \\ ${ }^{4}$ (Department of Community medicine, S.N Medical College, Agra, India) \\ ${ }^{2}$ Dr Ankur Goyal, ${ }^{\mathrm{MD}, \text { PDCC (Infectious Diseases) }}$ \\ ${ }^{2}$ Head of Department, Department of Microbiology Nodal officer SRL \& VDRL, \\ Officer In-Charge ICTC Sarojini Naidu Medical College, Agra (UP)-282002 \\ E-mail ID:agoyal79@yahoo.co.in Mobile No:91-9415061346
}

\begin{abstract}
Cholera is one of the most important diarrhoeal diseases in India and a major illness of public health importance. Recently there was an outbreak of acute watery diarrhoea in Mathura district, during late OctoberNovember 2016.

Objectives: To determine the cause, source and extent of the acute diarrhoeal disease outbreak in district of Mathura by conducting an environmental and microbiological investigation.

Materials and Methods: Water samples (1 from pond, 2 from municipal taps, 2 from tube wells and 3 from tanks) were collected from areas reporting the maximum number of cases of acute watery diarrhoea, and tested for diarrhoeagenic pathogens in the laboratory. Isolation and identification of pathogen was done according to the standard methodology.

Results: Of the eight water samples tested, four were found to be positive for $V$. cholerae. The major reason for the outbreak was traced to be contaminated water from one tank, one tap and two tube wells.

Conclusion: Our findings demonstrated that water supply of the public water sources, possibly contaminated by the nearby sewerage system, was the probable cause of acute watery diarrhoea outbreak in district of Mathura and the etiological agent was found to be V.cholerae. The people from this area have poor knowledge on proper hygiene. There is urgent need for public awareness against water borne diseases. Also, Mathura being a holy place, is visited by a large number of tourists, who also have access to these public water sources. Continuous surveillance of the outbreak is necessary to contain the spread of transmission.
\end{abstract}

Keywords: acute watery diarrhoea, outbreak, water samples

\section{Introduction}

Cholera is one of the most important diarrhoeal diseases in India and a major illness of public health importance [1]. The disease poses a lesser threat to developed countries which have appropriate standards of hygiene while it remains a challenge in India and other developing countries where access to safe drinking water and adequate sanitation facilities are often limited [2]. Cholera, essentially being a disease of poor sanitation, is linked to consumption of water and food from unsafe sources, such as, drinking water from tube-wells or river, drinking or bathing in lakes, eating at large funeral feasts and consumption of cold leftover foods [3]. Although in humans, several pathogens may be responsible for causing acute diarrhoea, it is essentially important to investigate Vibrio cholerae as the causative agent, because it can be fatal, causing severe dehydration and death within several hours and it is highly contagious [4]. Recently there was an outbreak of acute watery diarrhoea in Mathura district, during late October-November 2016, involving more than thousand people. We conducted an environmental and microbiological investigation to determine the cause, source and extent of this outbreak. As contaminated water plays an important role in the transmission of pathogens associated with acute watery diarrhoea, the current study mainly aimed to detect these diarrhoegenic pathogens in water collected from various public water souces of Mathura district, which could be responsible for the diarrhoea outbreak.

\section{Materials And Methods}

Water samples were collected from various public water sources in the affected locality of Mathura district, following an outbreak of acute watery diarrhoea. Water samples were collected in $500 \mathrm{~mL}$ bottles and transported immediately to the microbiology laboratory of SN Medical College, Agra for analysis. From each water sample, some water was directly poured into Mac Conkey broth and alkaline peptone water, respectively for enrichment. Mac Conkey broth was incubated for $18-24 \mathrm{hrs}$ and alkaline peptone water for $4-6 \mathrm{hrs}$ at $37^{\circ} \mathrm{C}$ 
Microbiological Investigation of water sources as cause of acute watery diarrhoea outbreak..

before subculture was done. Rest of the water sample was divided into two parts equally and each part was filtered through $0.22 \mu \mathrm{m}$ filter papers separately. The membrane filters were then enriched in $50 \mathrm{ml}$ of modified MacConkey broth at $37^{\circ} \mathrm{C}$ for $18-24 \mathrm{hrs}$ and alkaline peptone water (APW) ( $\mathrm{pH} \mathrm{8.4)} \mathrm{at} 37^{\circ} \mathrm{C}$ for $4-6 \mathrm{hrs}$, respectively and then cultured on selective media [5]. Thiosuphate citrate bile salt sucrose (TCBS) agar was used as selective media and subculture was also done on blood agar and Mac Conkey, incubated at $37^{\circ} \mathrm{C}$ for 18 to $24 \mathrm{~h}$ and processed for isolation of bacterial pathogens. Cultures were preliminarily screened by Hanging drop technique and colony morphology and the colonies with the characteristic appearance of $V$. cholerae were confirmed by biochemical tests as per the standard methods [2]. We interviewed the various persons like health workers and food safety department regarding information of water supply, drainage system and any recent events of watery diarrhoea.

\section{Results \& Discussion}

Of the eight water samples tested, four were found to be positive for $V$. cholerae, suggesting its major role in the outbreak. No gut pathogen was isolated in the rest of the water samples. The major reason for the outbreak was traced to be contaminated water from a tank, a tap and two tube wells. All these four water sources were found to be in close proximity, as both the tube wells were supplying the tank and the tap was also getting water supply from the same tank. On further investigation we found that a community toilet was present near the tube wells. The distance of the septic tank of community toilet was 20-25 ft from one tube well and 60-70 ft from the other tube well. To avoid bacterial contamination, the tube wells should be located not less than $15 \mathrm{~m}$ (50 feet) from likely sources of contamination [6]. Thus, chances of ground water contamination due to septic tank were high as one tube well (20-25 ft away) was clearly not at safe distance from the septic tank. Being a famous pilgrimage place, the community toilet of this area is always heavily rushed. Although the other tube well (60-70 ft away) was at a safe distance from the septic tank, however it was present near a sewer drain which could also be a source of ground water contamination. On the basis of the data of acute watery diarrhoea cases, collected from the district of Mathura, we mapped out these diarrhoea cases in relation to the sampled public water sources. The diarrhoea cases were clustered around and using the water sources that have been found positive for V.cholerae in the present study, thus suggesting that, contaminated water from these public water sources played an important role in the transmission of this pathogen, leading to an outbreak of cholera in Mathura district.

Ranjbar et al, also stated in their study that an outbreak of cholera occurred due to contaminated well water as all the patients had consumed well water before the onset of outbreak and the cultures of stool and well water samples also yielded V. cholerae [3]. Mahanta et al, in their study, reported a cholera outbreak due to consumption of the contaminated water of piped water supply, along with inadequate sanitation as $94.6 \%$ were practicing open field defecation and later spot mapping of cases was done and about 120 suspected cases were line listed [7]. Similarly, in the study of Kaistha et al, contaminated water of the public water sources, such as hand pumps, was an important source of cholera outbreak in the affected area which was confirmed by culture of faecal specimens from acute gastroenteritis cases and simultaneously water samples from the areas reporting the maximum number of cholera cases, both of which were positive for V.cholerae [1]. Bhunia et al. also reported an outbreak of cholera that affected a high-risk slum supplied by an old piped water supply with no regular chlorination and the probable source of infection was contaminated municipal piped water supply that had sucked the nearby sewage been contaminated by an index case-patient suffering from cholera [8].

In the present study, we also feel that recent outbreak of acute watery diarrhoea probably by $V$. Cholerae (As evidenced by clinical history but not confirmed microbiologically as V.cholerae) is due to contamination of water supply by sewerage system, as all the water supply and sewerage arrangement in this holy place was quite old and there was no regular chlorination of water as it was supplied by the tube wells. As a result of our investigation, the local authority closed the tubewells for water supply. Therefore, water sources and sanitation need to be improved and proper management of the excreta is necessary to avoid contamination of water sources. Low level of personal and domestic hygiene may have also led to extensive environmental contamination, resulting in contamination of these water sources. 


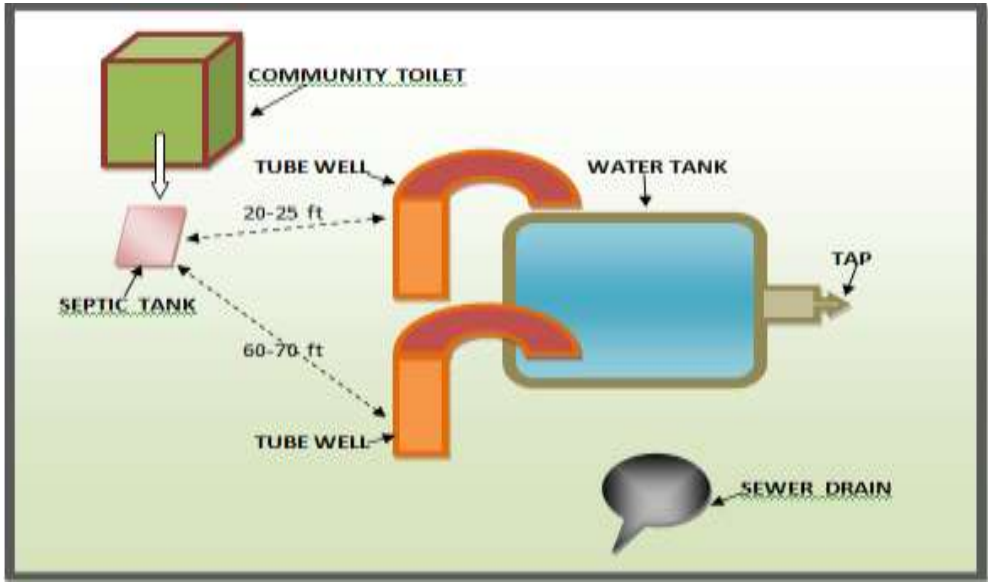

Figure 1: Diagramatic representation showing the four water sources, from which the water samples were found to be positive for $\mathrm{V}$. cholerae, in close proximity

\section{Conclusion}

Our findings demonstrated that water supply of the public water sources, possibly contaminated by the nearby sewerage system, was the probable cause of acute watery diarrhoea outbreak in district of Mathura and the etiological agent was found to be V.cholerae. Cholera is a serious public health threat, especially in a highly populated urban setting like Mathura district, where poor water and sanitation conditions are favorable for transmission of $V$. cholerae. Also, Mathura being a holy place, is visited by a large number of tourists who can also contract the infection from these contaminated public water sources and further spread outbreaks in their native places.

\section{Limitation of the study}

This research was conducted in resource limited setting, due to which we could not use serological and molecular methods to confirm our results.

\section{Acknowledgement}

The authors acknowledge the efforts of concerned authorities of Mathura for the study.

\section{References}

[1]. Kaistha N, Mehta M, Gautam V, Gupta V. Outbreak of cholera in \& around Chandigarh during two successive years (2002, 2003). Indian J Med Res 2005; 122(5):404-407

[2]. Dey S, Parande MV, Parande AM, Lakkannavar SL, Rathore PK, Mantur BG, et al. Twin outbreak of cholera in rural North Karnataka, India. Indian J Med Res 2014; $140: 420-426$

[3]. Ranjbar R, Rahbar M, Naghoni A, Farshad S, Davari A, Shahcheraghi F. A cholera outbreak associated with drinking contaminated well water. Arch Iran Med. 2011;14(5):339-40

[4]. Pun SB, Maharjan R, Shrestha D, Pokharel D, Shah Y, et al. An Outbreak of Vibrio cholerae in 2012, Kathmandu, Nepal. Trop Med Surg. 2013;1:115

[5]. Rafique R, Rashid MU, Monira S, Rahman Z, Mahmud MT, Mustafiz M, et al. (2016) Transmission of Infectious Vibrio cholerae through Drinking Water among the Household Contacts of Cholera Patients (CHoBI7 Trial). Front. Microbiol 2016;7: 110

[6]. Park K. Textbook of Preventive and Social Medicine. $20^{\text {th }}$ ed. Jabalpur: M/s Banarsidas Bhanot. p. 620.

[7]. Mahanta BN, Mahanta TG, Sinha R, Dutta A, Payeng D, Jawed Q. Investigation of a cholera outbreak in a tea garden of Sivasagar district of Assam. Indian J Community Med 2013;38:240-3

[8]. Bhunia R, Ramakrishnan R, Hutin Y, Gupte MD. Cholera outbreak secondary to contaminated pipe water in an urban area, West Bengal, India, 2006. Indian J Gastroenterol. 2009; 28: 62 - 64. 